\title{
ON THE MAIN BRANCHES OF THE PULMONARY ARTERY IN SOME VIPERIDAE
}

\author{
BY \\ L. D. BRONGERSMA, D.Sc. \\ Rijksmuseum van Natuurlijke Historie, Leiden
}

In all snakes, the Boidae and Xenopeltidae excepted, only the right lung is well developed, while the left lung is rudimentary or absent (BUTLER, 1895). The right lung consists of an anterior alveolar part that is strongly vascularized, and of a posterior smooth-walled air-sac that is anangious. Between these two parts a transitional zone may be present, in which the wall of the lung shows a faint reticulate pattern, and which receives some very fine branches from the pulmonary vessels. In a number of snakes, among which the Viperidae, the situation becomes more complicated. In these snakes the membrane that connects the dorsal ends of the incomplete tracheal cartilages has become greatly expanded, and this dorsal wall has developed an alveolar structure. CoPE (1894, p. 218) very aptly has named this the tracheal lung. When the tracheal lung has very strongly developed, it sometimes merges gradually into the right lung. In species with a rudimentary left lung, its opening into the trachea may be considered to mark the end of the trachea, and consequently also the beginning of the right lung. In other species a slight change in the structure of the alveoles may mark the boundary, but in a number of species it becomes a more or less arbitrary procedure to draw a boundary between the tracheal lung and the right lung. For the purpose of the present note it suffices, however, to consider as right lung that part of the respiratory tract that lies posterior to the middle of the heart.

The development of the tracheal lung, and the relative size of the alveolar part of the right lung and of the air-sac vary according to genera and species.

In Lachesis mutus (L.) the dorsal wall of the trachea has greatly expanded, but it does not show an alveolar structure; in this species the alveolar structure is present in the right lung posterior to the heart. Cerastes cornutus (L.), Atractaspis irregularis (Reinh.) and Atractaspis bibronii Smith have a very narrow tracheal lung, and in these species too the alveolar part of the right lung has well developed. In the other species the tracheal lung has strongly developed, and forms the main respiratory area; the alveolar structure of the 
lung may reach to slightly posterior of the heart, or the whole lung from the base of the ventricle of the heart posteriorly has become smooth-walled.

As a consequence of the presence of a tracheal lung, and the reduction of the alveolar area of the right lung, the main respiratory area is in front of the heart, instead of behind it. This is reflected in the course of the pulmonary vessels.

As far as I am aware, Schlemm (I827, pp. II8-II9, pl. VII fig. 3) was the first author to refer to this, when he described the anterior branches of the pulmonary artery in Vipera berus (L.) and in "Trigonocephalus mutus" (= Lachesis mutus (L.)). Several other authors (e.g., Gadow in Hoffman,, I886, pl. CXXXVI fig. 2; CoPE, I900, p. 693; BEDDARD, I906, pp. 36, 4I-44) have also mentioned that snakes with a tracheal lung possess branches of the pulmonary artery that pass forward from the heart. However, they do not mention the exact position of these arteries with regard to the lung or tracheal lung, and the situation is of ten more complicated than indicated in their papers. To ascertain the course of the main branches of the pulmonary artery, I examined 30 species of Viperidae, belonging to 13 genera, viz.,

\begin{tabular}{|c|c|}
\hline 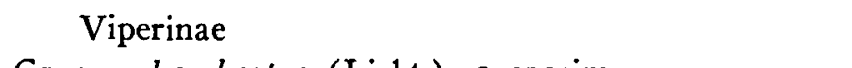 & \\
\hline Causus rhombeatus (Licht.), 3 specimens & \\
\hline Vipera berus (L.), 3 specimens & III \\
\hline Vipera russellii (Shaw), I specimen & III \\
\hline Bitis arietans (Merr.), 2 specimens & \\
\hline Bitis gabonica (Dum., Bibr. \& Dum.), I specimen & \\
\hline Cerastes cornutus (L.), 2 specimens & IV \\
\hline Echis carinatus (Schn.), I specimen & III \\
\hline Atheris chlorechis (Schl.), I specimen & III \\
\hline Atractaspis irregularis (Reinh.), 3 specimens & IV \\
\hline Atractaspis bibronii Smith, I specimen & IV \\
\hline Crotalinae & \\
\hline Agkistrodon piscivorus (Lac.), I specimen & III \\
\hline Agkistrodon rhodostoma (Boie), 2 specimens & III \\
\hline Lachesis mutus (L.), 3 specimens & II \\
\hline Bothrops atrox (L.), 2 specimens & I \\
\hline Bothrops jararucussu Lacerda, I specimen & \\
\hline Bothrops alternatus (Dum., Bibr. \& Dum.), I specimen & $\boldsymbol{L}^{+}$ \\
\hline Bothrops ammodytoides Leybold, I specimen & \\
\hline Bothrops bilineatus (Wied), I specimen & $\mathbf{2}^{-}$ \\
\hline Bothrops nummifer (Rüpp.), 2 specimens & III \\
\hline Bothrops sch'egelii (Berthold), 2 specimens & III \\
\hline Bothrops lansbergii (Schl.), I specimen & III \\
\hline Trimeresurus albolabris Gray, 3 specimens & III \\
\hline
\end{tabular}




$\begin{array}{lr}\text { Trimeresurus puniceus (Boie), I specimen } & \text { III } \\ \text { Trimeresurus wagleri (Boie), I specimen } & \text { III } \\ \text { Trimeresurus flavoviridis (Hall.), I specimen } & \text { III } \\ \text { Trimeresurus purpureomaculatus (Gray), 2 specimens } & \text { III } \\ \text { Trimeresurus monticola Gthr., I specimen } & \text { III } \\ \text { Sistrurus catenatus (Raf.), I specimen } & \text { III } \\ \text { Crotalus durissus L., I specimen } & \text { I } \\ \text { Crota'us scutulatus (Kenn.), I specimen } & \text { I }\end{array}$

Not only does the course of the branches of the pulmonary artery differ from that in snakes without a tracheal lung, but also among the Viperidae different types may be recognized. I have divided the species into five groups, which $I$ have indicated by roman numerals in the list given above.

I. Bitis arietans (Merr.) and Bitis gabonica (Dum., Bibr. \& Dum.). The pulmonary artery passes forward from the ventricle, and at the level of the anterior borders of the auricles it curves slightly to the dorsal side, and bifurcates (fig. I) ; one branch passes to the dorsal side of the respiratory tract, the other passes ventrally across the trachea to the left side. The dorsal branch again bifurcates into two arteries, one of which runs forward along the right dorsal side of the tracheal lung, while the other goes posteriorly along the right dorsal side of the lung. The ventral branch of the pulmonary is continued craniad along the left side of the trachea. At some distance from its origin it gives off a rather weak branch that curves posteriorly, and that supplies the left side of the posterior part of the tracheal lung and of the alveolar part of the right lung.

Thus in Bitis arietans and $B$. gabonica the main branches of the pulmonary artery consist of two anterior branches (one dorsal, one ventral) and of two posterior branches (also one dorsal and one ventral). The position of the pulmonary arteries with regand to the tracheal lung is shown in a schematic cross section (fig. 6). In a juvenile specimen of Bitis gabonica a distinct ligamentum arteriosum was found.

In Bitis nasicornis (Shaw), BEDDARD (1906, p. 36) mentions that the artery bifurcates into an anterior and a posterior branch. Probably the dorsal anterior branch and the ventral posterior branch have been overlooked.

In Bothrops atrox (L.), B. jararucussu Lacerda, B. alternatus (Dum., Bibr. \& Dum.), B. ammodytoides Leybold and $B$. bilineatus (Wied) the branching of the pulmonary artery is about the same as in Bitis arietans. The pulmonary artery also bifurcates into a dorsal and a ventral branch. The dorsal branch divides into an anterior and posterior artery. Of the ventral artery the anterior branch is much the stronger, and the posterior branch is very weak. In a young specimen of $B$. atrox the ventral pulmonary shows a small diverticulum that is connected to the left aorta by a ligamentum arteriosum (fig. 2).

Crotalus durissus L. and $C$. scutulatus (Kenn.) show the same branches of 
the pulmonary artery as the five species of Bothrops mentioned above (fig. 7). The anterior branch of the dorsal artery is very weak; it extends forward over a short distance only. In the anterior part of the tracheal lung the whole circumference is supplied by the anterior ventral artery. Gadow (in HoffMANN, I886, pl. CXXXVI fig. 2) figures only the anterior branches of the pulmonary artery in Crotalus (species not mentioned).

II. Lachesis mutus (L.). In front of the heart the pulmonary artery bifur-

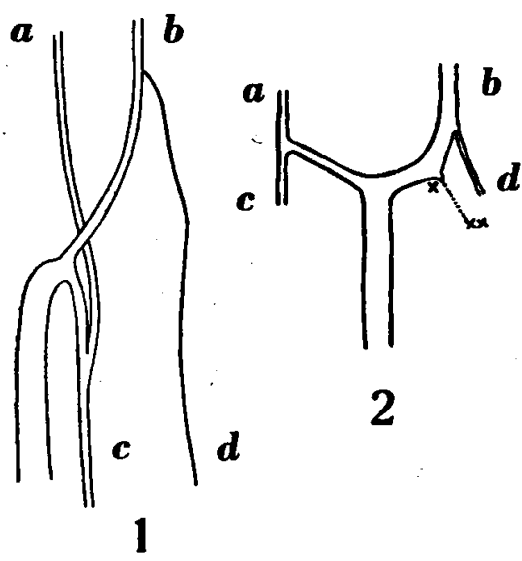

1

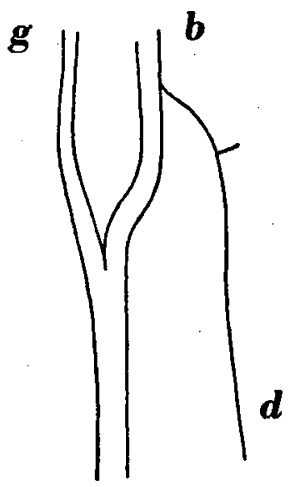

5

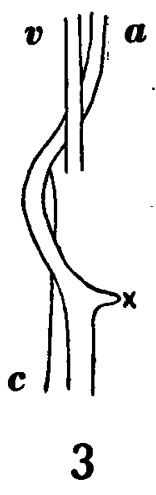

Figs. 1-5, main branches of the pulmonary artery, ventral view. Fig. 1, Bitis arietans (Merr.); fig. 2 , Bothrops atrox (L.); fig. 3, Vipera russellii (Shaw); fig. 4 , Cerastes cornutus (L.), the dotted line indicates the outline of the tracheal lung and lung; fig. 5, Causus rhombeatus (Licht.).

For the explanation of the letters, etc., see p. $6 \mathrm{r}$.

cates into a ventral and a dorsal artery. The ventral artery supplies the left ventral part of the tracheal wall ; this branch is very weak, and this is in agreement with the fact, that the tracheal wall is not alveolar. This ventral artery is much narrower than would be surmized from the figure and description by Schlemm (I827, p. II9, pl. VII fig. 3). No trace of a posterior branch of the ventral artery was found. The dorsal artery gives of $\mathrm{f}$ a small branch to the dorsal surface of the tracheal wall. The posterior branch of the dorsal artery is the largest branch; it passes to the alveolar area of the right lung. 

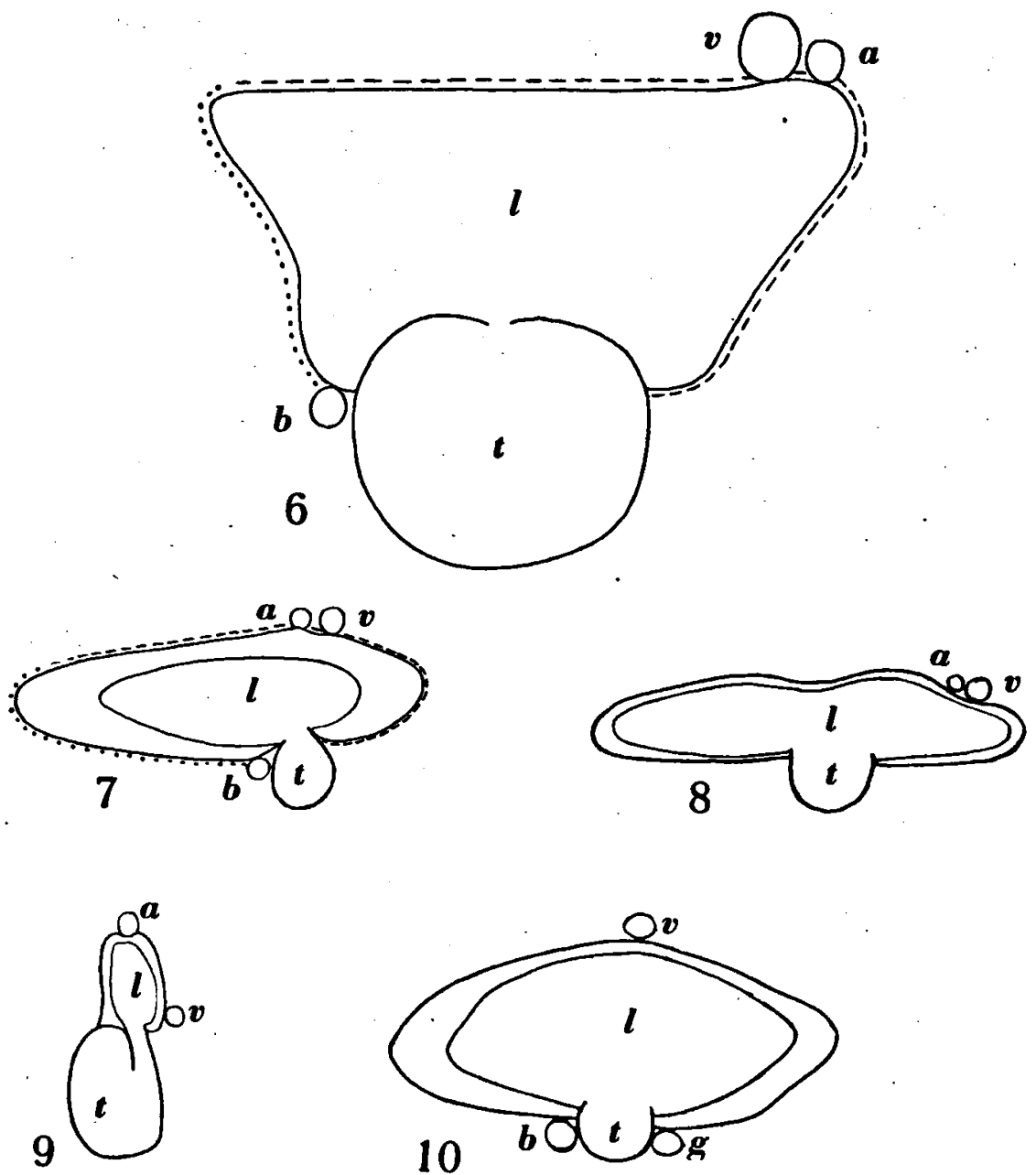

Figs. 6-10, diagrammatic drawings of cross sections of the tracheal lung to indicate the position of the pulmonary vessels; the cross sections are viewed from caudad, dorsal side above, left side at left of figure. Fig. 6, Bitis arietans (Merr.); fig. 7, Crotalus scutulatus (Kenn.): fig. 8, Trimeresurus puniceus (Boie); Fig. 9, Atractaspis irregularis (Reinh.) ; fig. 10, Causus rhombeatus (Licht.).

a, pulmonary artery to the dorsal surface of tracheal lung; $b$, idem to the ventral surface of tracheal lung; $c$, idem to the dorsal surface of right lung; $d$, idem to the ventral surface of right lung; e, branch of the pulmonary artery on the ventral surface of the lung in Cerastes cornutus (L.); $f$, pulmonary branch on the dorsal surface of the lung in Cerastes cornutus (L.); g, right ventral branch of the pulmonary artery in Causus rhombeatus (Licht.); $\mathrm{l}$, tracheal lung; $t$, trachea; $v$, anterior branch of the vena pulmonalis; $X$, diverticulum of pulmonary artery, $X X$, ligamentum arteriosum; the dotted line in figs. 6 and 7 indicates the area supplied by the ventral branch of the pulmonary artery; the broken lire in figs. 6 and 7 indicates the area supplied by the dorsal bra'xch of the pulmonary artery. 
III. In a number of species, viz., those that I examined from the genera Vipera (fig. 3), Echis and Atheris among the Viperinae, and in Agkistrodon, Trimeresurus, Bothrops nummifer (Rüpp.), B. schlegelii (Berthold), B. lansbergii (Schl:) and Sistrurus among the Crotalinae, the pulmonary artery shows a small diverticulum, directed ventrally and to the left. It is situated at the point where in the species of groups I and II the ventral branch of the pulmonary artery arises. This diverticulum may represent, therefore, the remnant of a ventral artery, and also the remnant of the ductus arteriosus (ductus Botalli) of the embryo. In some specimens it was connected to the left aortic arch by a ligament, that is in favour of the latter explanation (ligamentum arteriosum). The main stem of the pulmonary artery consists of the dorsal branch. It passes slightly anteriorly and round the right side of the tracheal lung towards the right dorsal surface of the latter (fig. 3). There it divides into an anterior and a posterior branch. The anterior branch, which is the stronger of the two curves dorsally across the anterior pulmonary vein and passes forward at the left side of this vein (fig. 8). The narrow posterior branch passes posteriorly to the small alveolar part of the lung.

IV. In the two species of Atractaspis the pulmonary artery curves dorsally and then posteriorly over the dorsal surface of the heart. After passing through the curve the pulmonary gives off a very small branch that bifurcates, one branch going to the dorsal surface of the tracheal lung (fig. 9), the other to the dorsal surface of the right lung. The main stem is continued posteriorly over the ventral surface of the right lung, and gives off a small branch to the rudimentary left lung.

A somewhat similar situation is found in Cerastes cornutus (L.) (fig. 4). In this species too the only pulmonary curves dorsally and posteriorly over the dorsal surface of the heart. When it reaches the heart it bifurcates into a dorsal and ventral branch. The dorsal branch gives of a small artery to the dorsal surface of the weakly developed tracheal lung; the main part of this dorsal artery passes to the dorsal surface of the lung where it soon ends in small ramifications. In a second specimen this dorsal artery of the right lung is somewhat better developed; it runs obliquely across the dorsal surface of the lung and bends round the left side of the latter; its posterior part is seen on the left ventral side of the lung.

V. Causus rhombeatus (Licht.). The pulmonary artery bifurcates in front of the heart, but both branches remain on the ventral surface of the tracheal lung, one artery on each side of the trachea (figs. 5, 10). The artery on the left side of the trachea gives of $f$ a small branch that curves posteriorly; it goes to the ventral surface of the lung.

The above notes show that considerable differences exist in the pulmonary arteries of the Viperidae. Instead of a primary division into anterior and posterior branches, as indicated in literature, the main division is into a dorsal and a ventral branch. It may be remembered that in snakes with two lungs, 
e.g., Python reticulatus (Schn.), the arteria pulmonalis sinistra arises from the ventral side of the common stem, while the arteria pulmonalis dextra takes a more dorsal course. In Bitis, in a number of Bothrops species, and in Crotalus the ventral and dorsal branches of the pulmonary artery agree in this respect with the left and right pulmonary arteries in Python reticulatus. According to Hochstetter (1902, pp. 99-100) the left sixth aortic arch (from which the left pulmonary has derived) is present in embryo's of snakes that have only one lung; it functions as ductus arteriosus. Vipera, Cerastes, Atractaspis, Trimeresurus, Bothrops nummifer, $B$. schlegelii and $B$. lansbergii show a diverticulum that is the remnant of the ductus arteriosus (left sixth aortic arch), and therefore, it is also the remnant of the basal part of the left pulmonary. In a young specimen of Bothrops atrox a similar diverticulum was found on the ventral pulmonary at some distance from the latter's origin (fig. 2) it is connected to the left aorta by a ligament (ligamentum arteriosum). The basal part of the ventral pulmonary in these snakes, therefore, may be surmized to be identical with the basal part of the left pulmonary artery in two-lunged snakes. The anterior branch will have arisen from this left pulmonary in the snakes with a tracheal lung. The dorsal pulmonary in the Viperidae is no doubt identical with the right pulmonary artery of the twolunged snakes. In Atractaspis and Cerastes the right pulmonary artery shows a secondary division into a ventral and dorsal branch. Finally, the right pulmonary in Causus has lost all connection with the right lung; it consists only of an anterior branch that in this species remains on the ventral side of the tracheal lung.

As far as the limited number of species and specimens examined by me allow of definite conclusions, the main branches of the pulmonary artery appear to be constant in each species and in the majority of the genera. The only exception is the genus Bothrops, in which B. nummifer, B. schlegelii and $B$. lansbergii differ from the other species. It may be mentioned that these three belong to the group of species that have single subcaudals, while the other Bothrops species examined by me belong to the group of species having paired subcaudals. Further studies will have to show, whether the three species mentioned above should be referred to a separate genus.

\section{LITERATURE}

Beddard, F. E., I906. Contributions to the Anatomy of the Ophidia. Proc. Zool. Soc. London, pp. 12-44, figs. 2-1 I.

BurLer, G. W., 1895. On the complete or partial suppression of the right lung in the Amphisbaenidae and of the left lung in Snakes and Snake-like Lizards and Amphibians. Proc. Zool. Soc. London, pp. 691-712, pl. XL.

Cope, E. D., I894. On the Lungs of the Ophidia. Proc. Amer. Philos. Soc., vol. XXXIII, no. 145, pp. 217-224, pls. XI-XVI. 
Cope, E. D., 1900. The Crocodilians, Lizards, and Snakes of North America. Rept. U.S. National Museum for the year ending June 30, I898, pp. 153-1270, figs. 1-347, pls. 1-36. HochsteTTER, 1902. Die Entwicklung des Blutgefässsystems. Handb. Entwicklungslehre d. Wirbeltiere (O. Hertwig), vol. 3, pt. 2, pp. 21-166, figs. 8-177.

HofrmanN, C. K., 1886. Reptilien. I.II. Schlangen und Entwicklungsgeschichte der Reptilien. Bronn's Klassen und Ordnungen des Thier-Reichs, vol. 6, sect. III, pl. CXXXVI.

Schiemm, F., 1827. Anatomische Beschreibung des Blutgefässystems der Schlangen. Zeitschr. f. Physiol. (Tiedemann \& Treviranus), vol. 2, pp. IOI-124, pl. VII. 